\title{
Immune Dysfunction in Cirrhosis
}

\author{
Mohd Talha Noor* and Piyush Manoria \\ Department of Gastroenterology, Sri Aurobindo Medical College and Post Graduate Institute, Indore, India
}

\begin{abstract}
Cirrhosis due to any etiology disrupts the homeostatic role of liver in the body. Cirrhosis-associated immune dysfunction leads to alterations in both innate and acquired immunity, due to defects in the local immunity of liver as well as in systemic immunity. Cirrhosis-associated immune dysfunction is a dynamic phenomenon, comprised of both increased systemic inflammation and immunodeficiency, and is responsible for $30 \%$ mortality. It also plays an important role in acute as well as chronic decompensation. Immune paralysis can accompany it, which is characterized by increase in antiinflammatory cytokines and suppression of proinflammatory cytokines. There is also presence of increased gut permeability, reduced gut motility and altered gut flora, all of which leads to increased bacterial translocation. This increased bacterial translocation and consequent endotoxemia leads to increased blood stream bacterial infections that cause systemic inflammatory response syndrome, sepsis, multiorgan failure and death. The gut microbiota of cirrhotic patients has more pathogenic microbes than that of noncirrhotic individuals, and this disturbs the homeostasis and favors gut translocation. Prompt diagnosis and treatment of such infections are necessary for better survival. We have reviewed the various mechanisms of immune dysfunction and its consequences in cirrhosis. Recognizing the exact pathophysiology of immune dysfunction will help treating clinicians in avoiding its complications in their patients and can lead to newer therapeutic interventions and reducing the morbidity and mortality rates.
\end{abstract}

Citation of this article: Noor MT, Manoria P. Immune dysfunction in cirrhosis. J Clin Transl Hepatol 2017;5(1):50-58. doi: 10.14218/JCTH.2016.00056.

Keywords: Cirrhosis; Immune dysfunction; Inflammation; Liver disease.

Abbreviations: $A C L F$, acute on chronic liver failure; AICD, activation-induced cell death; $\mathrm{BT}$, bacterial translocation; CAID, cirrhosis-associated immune dysfunction; CHB, chronic hepatitis B; CRP, c-reactive protein; DAMP, danger-associated molecular pattern; GM-CSF, granulocyte macrophage colony-stimulating factor; $\mathrm{HBeAg}$, hepatitis $\mathrm{B}$ e antigen; HE, hepatic encephalopathy; HLA-DR, human leukocyte antigen-D related; IFN, interferon; IL, interleukin; LPS, lipopolysaccharide; MAMP, microbial-associated molecular pattern; MBL, mannose-binding lectin; MCP, monocyte chemoattractant protein; MHC, major histocompatibility complex; MLN, mesenteric lymphadenopathy; NFK $\beta$, nuclear factor kappa $\beta$; NK, natural killer; NOD, nucleotide binding oligomerization; PAMP, pathogen-associated molecular pattern; PRR, pattern recognition receptor; SBP, spontaneous bacterial peritonitis; SIRS, systemic inflammatory response syndrome; TGF, transforming growth factor; TLR, toll-like receptors; TNF, tumor necrosis factor.

Received: 31 October 2016; Revised: 20 January 2017; Accepted: 8 February 2017 * Correspondence to: Mohd Talha Noor, Department of Gastroenterology, Sri Aurobindo Medical College and Post Graduate Institute, Indore 453 111, India. Tel: +917314231751, +91-8305421496, Fax: +91-7314231012, E -mail: noorpgi@gmail. com, noorpgi@yahoo.com

\section{Introduction}

Cirrhosis and its complications are a major cause of morbidity and mortality at the community level. Liver has a homeostatic role in the body's immunity and cirrhosis due to any etiology disrupts this homeostasis. Cirrhosis-associated immune dysfunction (CAID) is the acquired alteration of both innate and acquired immunity ${ }^{1}$ and leads to immunodeficiency as well as systemic inflammation, ${ }^{2}$ ultimately leading to around $30 \%$ mortality. ${ }^{3}$ Immunodeficiency in cirrhosis is due to derangement of local immunity of liver and of systemic immune cells. The systemic inflammation results from persistent immune cell stimulation, leading to production of various proinflammatory cytokines. ${ }^{2}$

In the CAID condition, there is enhanced gut translocation of bacteria that can lead to endotoxemia and increased cytokines, thereby resulting in an exaggerated inflammatory host response and increased occurrence of systemic bacterial infection that can progress to septic shock, multiorgan dysfunction and even death. ${ }^{4-8}$ Initially, in CAID, there is increased systemic inflammation in stable decompensated cirrhosis, changing to a predominantly immunodeficient state in severe decompensated cirrhosis and acute on chronic liver failure (ACLF). ${ }^{2}$ The extent of immune dysfunction is directly related to severity of liver injury, ${ }^{3}$ and the maximum dysfunction is seen in alcoholic cirrhosis. ${ }^{9}$ Therefore, gaining a comprehensive and precise understanding of this immune dysfunction is necessary for prevention, early diagnosis and proper treatment of infections in cirrhosis to improve chances of patient survival.

\section{Immunity and liver}

The innate immune system is made of cellular and humoral components, and it contains pattern recognition receptors (PRRs), antimicrobial peptides, immune cells (i.e. macrophages, dendritic cells, natural killer (NK) cells, NK-T cells), the complement system and various cytokines. Human innate immunity has surface and intracellular PRRs that recognize the microbial danger signals by recognizing pathogenassociated molecular patterns (PAMPs), ${ }^{10}$ microbial-associated molecular patterns (MAMPs) ${ }^{11}$ or danger-associated molecular patterns (DAMPs), ${ }^{12}$ after which they initiate an immune response. PAMPs are conserved structures vital to pathogens, but which cannot be mutated by the pathogen in order to escape innate immunity..$^{13,14}$ They are present in microbes and absent in eukaryotes. ${ }^{13,14}$ DAMPs, on the other hand, represent damaged cells of the host (i.e. human system) which are a threat to self. ${ }^{12}$

PRRs are present in immune cells, as well as in liver parenchymal cells. The recognition of any pathogen molecules 
by PRRs leads to activation of the complement cascade, cytokines, antimicrobial peptides and dendritic cells, resulting in a complex interplay of pro- and anti-inflammatory responses and immunogenic and suppressive responses in the host. ${ }^{10}$ Macrophages and dendritic cells are mononuclear phagocytes derived from monocytes and are efficient antigen presenting cells involving the major histocompatibility complex-II (MHC-II) of T cells in the adaptive immune system. ${ }^{15}$ Macrophages are cells of diverse shape and location. In the liver, they are known as Kupffer cells-flattened cells present in the hepatic sinusoids. ${ }^{15}$ Adaptive immunity is dependent on innate immunity for its antigen presentation and cytokine production, as without these it will be ineffective. ${ }^{15} \mathrm{Also}$, monocytes are central mediators of the immune response and secrete interleukin-1 (IL-1) and tumor necrosis factor- $\alpha$ (TNF- $\alpha$ ) which are responsible for recruitment of inflammatory cells. ${ }^{16}$

Liver is the major source of PRRs in the body, like C-reactive protein (CRP), lipopolysaccharide (LPS)-binding protein, peptidoglycan recognition protein and soluble CD14, ${ }^{17-19}$ and it expresses various PRRs, like Toll-like receptors (TLRs), nucleotide binding oligomerization (NOD)-like receptors and RNA helicases. ${ }^{2}$ TLRs recognize microbes on the cell surface. To date, 10 TLRs have been discovered in humans, and they harbor a common intracellular domain but a unique extracellular domain. ${ }^{20}$ Liver is the source of mRNA for all TLRs. ${ }^{21,22}$ Various parenchymal and non-parenchymal cells of liver express various TLRs. ${ }^{23-25}$ Also, immune cells of liver express various TLRs. T lymphocytes and NK cells expresses TLR 1, 2, 4, 5 and 9 and B lymphocytes expresses TLR 1, 6, 7, 9 and $10 .{ }^{26}$ Stellate cells of liver also express TLR 4 and 2 as well as CD14 and respond to activation by production of proinflammatory cytokines. ${ }^{27-30}$ Kupffer cells (the liver macrophage) are scavenger cells that are exposed to gut-derived bacteria, endotoxins and various microbes and their products. Once activated, they release various cytokines, prostaglandins, nitric oxide and reactive oxygen species, making them actively involved in liver innate immunity. ${ }^{31}$ Kupffer cells and endothelium of space of Disse express TLR2 following LPS stimulation. ${ }^{32}$ TLR2 is also accumulated near the hepatocyte plasma membrane after LPS challenge. Liver is also the main source of the complement system, which is responsible for regulation of the immune system and opsonic and cytotoxic activities.

Adaptive immunity is the lymphocyte-mediated immune response against specific microbial agents and is essential for complete and effective immunity in the body. Adaptive immunity is a highly specialized immunity that provides longlasting protection, and it is the basis for vaccination. The adaptive immunity is acquired during the lifetime of an organism and prepares the body for future challenges. It is mediated by $B$ and $T$ lymphocytes and its profile is specific, diverse and has a memory. The $B$ cells are responsible for humoral immunity, and the T cells are responsible for cellmediated immunity. Liver contains lymphocytes throughout its parenchyma and portal tracts. In the liver, $\mathrm{CD} 8^{+} \mathrm{T}$ cells are more frequent than $\mathrm{CD} 4^{+} \mathrm{T}$ cells, and memory cells are more frequent than blood cells. ${ }^{10}$

\section{Immunological dysfunction in cirrhosis}

\section{Innate immune dysfunction}

Cirrhosis affects innate immunity by impairing the synthesis and function of PRRs and various proteins, thus reducing the bactericidal capacity of that body. ${ }^{10}$ Different PRRs recognize different PAMPs. Among the PRRs, TLRs are most extensively studied and have a major influence in CAID. ${ }^{23,33,34}$ TLRs have an important role to play in the pathogenesis of various hepatic disorders, such as non-alcoholic fatty liver disease, alcoholic liver disease, viral hepatitis, autoimmune liver disease, hepatic fibrosis and liver cancer. ${ }^{35}$

Acquired alteration of TLRs and their signaling pathways are a major mechanism of innate immunity dysfunction in cirrhosis. ${ }^{34}$ This phenomenon may be due to prolonged exposure of bacteria, its products and PAMPs, as a result of the loss of barrier function related to loss of tight junctions, widening of intercellular spaces (which increases the gut translocation), presence of toxic agents (i.e. ethanol) and by their production by damaged hepatocytes. ${ }^{36}$ Gut flora can promote alcoholic liver disease by activating TLRs but this process can be reduced by altering the gut microbiota by administration of antibiotics and probiotics. ${ }^{37}$

Recent studies have shown that hepatitis $B$ e antigen ( $\mathrm{HBeAg}$ )-positive chronic hepatitis $\mathrm{B}(\mathrm{CHB})$ patients show down-regulation of TLR2 and that HBeAg-negative CHB patients show up-regulation of TLR2, suggesting its expression may be responsible for rapid progression of disease in the HBeAg-positive $\mathrm{CHB}$ patients. ${ }^{38}$ Functional impairment of TLR2 and TLR4 is one of the major reasons for immune dysfunction and risk of infection in cirrhotic patients. ${ }^{39}$ Both of these TLRs activate nuclear factor kappa $\beta$ (NFK $\beta$ ) in liver cells. ${ }^{40}$ Studies have shown decreased TLR2 function in early cirrhosis ${ }^{41,42}$ but decreased TLR4 function in advanced cirrhosis only. ${ }^{41,43-46}$ A study performed by Nischelke et al. ${ }^{47}$ has shown that TLR2 polymorphisms and NOD2 variants increase the susceptibility for spontaneous bacterial peritonitis (SBP) in patients with cirrhosis with ascites. Both of these defects were also found to be associated with reduced levels of NFK $\beta$ activation, which would lead to decreased activation of proinflammatory cytokines. Further studies by Bruns et al. ${ }^{48}$ have shown an increased risk of SBP in cirrhotics carrying the TLR2 R753Q polymorphism, in particular. Guarner-Argente et al. also showed that patients with the TLR4 D299G polymorphism had more infections and bacteremia. ${ }^{49}$

Impaired monocyte function is also a contributor to CAID, leading to defects in chemotaxis, phagocytosis, superoxide degeneration and production of lysosomal enzymes. ${ }^{50-53}$ Immune paralysis, which is defined as decreased human leukocyte antigen-D related (HLA-DR) expression of monocytes, is a well-known feature in ACLF and septic shock but it was recently found also in patients with liver cirrhosis. ${ }^{16}$ Immune paralysis is characterized by increase in anti-inflammatory cytokines, like IL- 6 and IL-10, and suppression of proinflammatory cytokines, like IL-1 and TNF- $\alpha .{ }^{17,44,45,54}$ Immunomodulator agents such as the granulocyte macrophage colony-stimulating factor (GM-CSF) and interferongamma (IFN- $\gamma$ ) can improve monocyte functions and should be investigated further. ${ }^{17}$ Endotoxemia, possibly through an IL-10-mediated mechanism, contributes to down-regulation of HLA-DR in cirrhotic patients. ${ }^{45}$ These low HLA-DR expressing monocytes have decreased production of proinflammatory cytokines, such as TNF- $\alpha$, and nitric oxide synthetase as well as allostimulatory activity. ${ }^{45}$ Avi et al. ${ }^{53}$ has shown decreased monocyte function in liver cirrhosis as measured by phagocytosis and killing of Candida albicans and Candida pseudotropicalis. Monocytes consist of the classical $\mathrm{CD} 14^{+} \mathrm{CD} 16^{-}$types and the non-classical $\mathrm{CD} 14^{+} \mathrm{CD} 16^{+}$ types. In chronic liver disease patients, there is marked increase in non-classical $\mathrm{CD} 14^{+} \mathrm{CD} 16^{+}$subsets, and this 
occurrence correlates with collagen-producing hepatic stellate cell activation, proinflammatory cytokines expression and clinical progression. ${ }^{55}$ Low lymphocyte-to-monocyte ratio has been postulated as an independent prognostic marker in liver cirrhosis. ${ }^{56}$

CD163 is a specific marker for macrophage activation and is shed into the circulation in a soluble form (SCD163). ${ }^{57}$ In cirrhosis, it increases in conjunction with increasing ChildPugh score and shows a strong correlation with the hepatic venous pressure gradient and thus with portal hypertension. ${ }^{58}$ Waismann et al. ${ }^{59}$ has demonstrated SCD163 as an independent risk factor for death and variceal bleeding in cirrhotic patients, raising the possibility of its development as a new pharmacological target in the future. Studies have shown that peritoneal macrophages of cirrhotic patients are associated with SBP by producing nitric oxide and angiogenic peptides. $^{60}$

Monocyte chemoattractant protein-1 (MCP-1) plays an important role in CAID. Its level is increased in ascites of cirrhotic patients as compared to controls, and it plays a major role in development and course of SBP. Erwin et al. ${ }^{60}$ demonstrated that in patients with alcoholic liver cirrhosis the 2518 MCP-1 genotype AA is a risk factor for development of SBP. Moreover, Muhlbauer et al. ${ }^{61}$ has shown that inheritance of the 2518 MCP-1 G allele predisposes patients infected with the hepatitis $C$ virus to more severe hepatic inflammation and fibrosis. Finally, Tonan et al. ${ }^{62}$ reported that Kupffer cell dysfunction contributes to the pathogenesis of non-alcoholic steatohepatitis, as CD14-positive Kupffer cells increase along with increase in necroinflammation grade and fibrosis stage.

Neutrophils, which are the first-line of defense against bacterial infection, are also impaired in cirrhotics. On the one hand, this creates an impaired ability to deliver neutrophils to the infective focus, while, on other hand, this generates a reduced phagocytic activity of the neutrophils as compared to those in the healthy population. Liver is the main site of clearance of various cytokines, like IL- 1, IL- 3 , IL- 6 , TNF- $\alpha$, transforming growth factor- $\beta$ (TGF- $\beta$ ), IFN- $\gamma$ etc. In cirrhosis, however, liver is unable to clear the cytokines, which can lead to persistent activation of peripheral blood neutrophils ${ }^{63}$ and subsequently impair the neutrophilc functions like migration and phagocytosis. ${ }^{64}$ Also, increased endotoxin absorption and bacterial translocation (BT) leads to persistent elevation of cytokines. Removing endotoxins in vitro ${ }^{65}$ and reducing endotoxemia in vivo with probiotics ${ }^{46}$ improves polymorphonuclear leukocyte function in cirrhosis. Fiuza et al. ${ }^{66}$ demonstrated that cirrhotic patients exhibit deficient transendothelial migration and G-CSF enhances neutrophil transendothelial migration.

Recent studies have demonstrated that G-CSF therapy mobilizes $\mathrm{CD}^{+} 4^{+}$cells and improves the survival of ACLF patients. ${ }^{67,68} \mathrm{G}$-CSF therapy also significantly improved the rate of 2-month survival, reduced the Child-Turcotte-Pugh, model for end-stage liver disease, and sequential organ failure assessment scores, and prevented the occurrence of sepsis, hepatorenal syndrome and hepatic encephalopathy. ${ }^{67}$

\section{Adaptive immune dysfunction}

Adaptive immune dysfunction is also common in cirrhotic patients. The various defects in $B$ and $T$ cell functions in alcoholic liver disease have been known for a long time. Nourieta et al. ${ }^{69}$ demonstrated a broad defect of $T$ cells and hyperactivity of $B$ cells in patients with alcoholic liver disease. Specifically, these patients have circulating IgG and T lymphocytes that recognize epitopes against lipid peroxidationderived antigens and are associated with an increase in hepatic production of proinflammatory cytokines and chemokines. Doi et al. ${ }^{70}$ reported that memory $\mathrm{CD} 27^{+} \mathrm{B}$ cells were reduced in the peripheral blood of patients with cirrhosis, independent of etiology, and that this reduction led to impaired TNF- $\beta$ and IgG production, vaccine hyporesponsiveness and susceptibility to bacterial infection.

The Th1/Th2 lymphocyte ratio is important, as Th1 expresses antifibrotic cytokines and Th2 expresses profibrotic cytokines. In cirrhosis, $\mathrm{CD}^{+}$cells are elevated, thereby decreasing the $\mathrm{CD} 4^{+} / \mathrm{CD}^{+}$cell ratio and favoring the fibrogenic process. ${ }^{10} \mathrm{~A}$ study performed by Marquez et al. ${ }^{71}$ showed intense derangement of monocytes and $T$ cells of the immune system in patients with liver cirrhosis. Importantly, there is prolonged activation of T lymphocytes as a result of the prolonged antigenic stimulus in cirrhosis. Activated $\mathrm{CD}^{+}$and $\mathrm{CD}^{+}$lymphocytes show increase in apoptosis markers and activation-induced cell death (AICD), presumably made in order to maintain lymphocyte homeostasis. Compared with healthy controls, cirrhotic patients show higher expression of the apoptosis marker $\mathrm{CD}^{+} 5^{+}$in their memory cell population. ${ }^{10}$ These T cells are unable to proliferate after new antigenic load, which leads to immunosuppression secondary to exhaustion of the adaptive immune response. The various mechanisms of immune dysfunction described herein for cirrhosis are presented in Fig. 1.

It is long known that serum IgA level is enhanced in alcoholic liver disease, but the exact mechanism causing it remains to be fully elucidated. ${ }^{72}$ Silvain et al. ${ }^{73}$ demonstrated that altered Fc alpha $\mathrm{R}$ expression in monocytes leads to receptor saturation and increases the absolute level of IgA and IgA immune complex, due to defective clearance in alcoholic cirrhosis. Massonnet et al. ${ }^{74}$ demonstrated that enhanced IgA production by CpG led to activation of B cells in alcoholic liver cirrhosis, compared to the mechanism observed in healthy donors, and this was due to the intrinsic ability of these cells to produce more IgA.

\section{Complement system and cirrhosis}

The complement system plays an important role in both innate and adaptive immunity, and protects the body from microbial infections. Hepatocytes are the major source of synthesis of complement factors. Low opsonin activity and reduced $\mathrm{C} 3$ complement level increases susceptibility to infection in cirrhotic patients. ${ }^{75,76}$ Reduced C3 and C4 complement levels are observed in cirrhotics, and this phenomenon is due to decreased synthesis as a result of liver dysfunction and increased consumption of the factors due to persistent complement activation.

Hillebrand et al. ${ }^{77}$ has demonstrated a critical role of $\mathrm{C5}$ and $\mathrm{C} 5 \mathrm{aR}$ in the pathogenesis of liver fibrosis. Immunocytochemistry studies have shown that expression of C5aR1 significantly increased on hepatic stellate cells during transformation to myofibroblast. Also, Strey et al. ${ }^{78}$ has found $\mathrm{C} 3 \mathrm{a}$ and $\mathrm{C} 5 \mathrm{a}$ to be essential for liver regeneration. In $\mathrm{C} 3$ and $\mathrm{C} 5$ knock-out mice, liver regeneration was severely impaired and was restored after reconstitution with the factors. ${ }^{78}$ Increased susceptibility of Pneumococcus pneumonia in cirrhosis has also been demonstrated due to insufficient deposition of complement C3 on the surface of lungs. ${ }^{79}$ Altotjay 
Noor M.T. et al: Immune dysfunction in cirrhosis

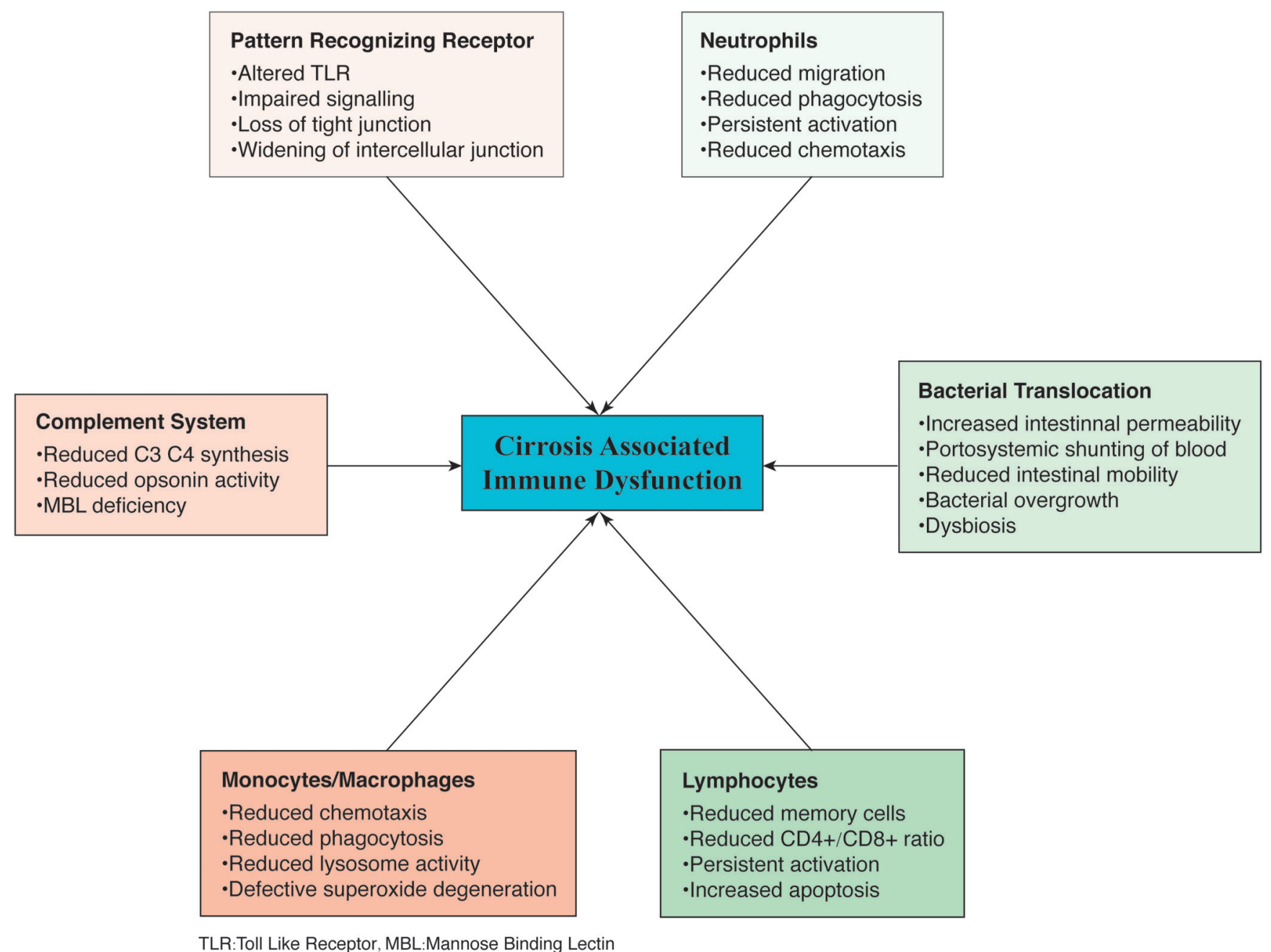

Fig. 1. Mechanisms of immune dysfunction in cirrhosis.

et al. ${ }^{80}$ has found mannose-binding lectin (MBL) deficiency to be associated with higher infection rate in liver cirrhosis. Moreover, significant reduction in MBL levels were observed in advanced cirrhosis, and levels $<100 \mathrm{ng} / \mathrm{mL}$ were associated with more bacterial infection in cirrhosis. ${ }^{80}$

\section{Bacterial translocation}

BT is migration of bacteria or their products (i.e. lipopolysaccharides, peptioglycans, muramyl dipeptides, bacterial DNA) from intestinal lumen to mesenteric lymph nodes (MLNs). ${ }^{81}$ BT is increased in cirrhotics. 5,6 It has also been associated with the occurrence of SBP. ${ }^{5,6}$ Pathological BT has been characterized as the 'Achilles heel' of cirrhosis.

Factors leading to increased BT in cirrhotics are impaired humoral and cellular immunity, ${ }^{82}$ portosystemic shunting of blood, ${ }^{83}$ decrease intestinal mobility, ${ }^{82}$ increased intestinal permeability ${ }^{84}$ and bacterial overgrowth. ${ }^{85}$ Studies have shown that after administration of radiolabeled Escherichia coli to cirrhotic rats, the bacteria are found not only in the gut lumen but also in the MLNs and ascites. ${ }^{86}$ Also, same bacterial species have been grown in ascites and MLNs from rats with cirrhosis. 87
Due to portosystemic shunting, there is reduced liver clearance of gut-derived bacteria and their products from the portal circulation. There is also reduced intestinal mobility in cirrhosis due to prolonged orocecal time, which is mainly due to increased pylorocecal transit time. ${ }^{88}$ Chang et al. ${ }^{89}$ have shown that cirrhotics with a history of SBP have more severe small intestinal motility dysfunction. Motor abnormalities have been observed in the small intestine, including changes in contraction pattern and increase in mean duration of the migratory motor complex. ${ }^{90}$

TLR2 ${ }^{48}$ and NOD- $2^{91}$ mutations have been linked with BT and SBP in cirrhosis. NOD-2 protein recognizes bacterial products and stimulates an immune reaction to limit the entry of bacteria across the gut by activation of NFK $\beta$ signaling. ${ }^{91}$ NOD-2 gene polymorphism has been described an important genetic risk factor for BT and SBP and also for reduced survival in western populations. ${ }^{91}$ Permeability of the intestinal wall is increased in cirrhosis and is one of the contributory factors for the development of SBP and hepatic encephalopathy. Permeability of the gut wall may be affected by edema of splanchnic tissue, due to congestion of the venous and lymphatic systems. $^{92}$ 
Keshavarzian et al. ${ }^{93}$ has shown that chronic liver injury in heavy drinkers is associated with leaky gut, as evidenced by increased urinary sucrose excretion after oral administration. A similar result has been reported by Toh et al. ${ }^{94}$ after oral phenolsufonphthalein absorption test in patients with liver cirrhosis. Campillo et al. ${ }^{95}$ has shown that impairment of the intestinal function barrier is related to severe septic complications in cirrhosis. Paramo et al. ${ }^{96}$ studied the role of propranolol in cirrhotic rats with ascites and found that it increases intestinal motility and decreases the bacterial overgrowth and translocation; thus, it may serve to prevent SBP in cirrhosis. Finally, a meta-analysis performed by Senzolo et al. ${ }^{97}$ has also concluded that beta-blockers have a role in preventing SBP in cirrhosis; although, randomized controlled trials in humans are still needed to confirm this finding.

\section{Gut microbiota in cirrhosis}

The gut and liver are in constant touch with each other, through the portal vein. The fecal microbiota in cirrhosis differs from that of the healthy population. In cirrhosis, there is change in the bacteroides/fermicutes ratio and more prevalence of pathogenic microbes like the Enterobacteriaceae and Streptococcaceae, as well as less prevalence of beneficial microbes like the Lachnospiraceae, and it may affect the prognosis. ${ }^{98}$ The change in the microbiota in cirrhosis disturbs the intestinal immune homeostasis, favors BT and impairs the host defense against them, and contributes to the development of hepatic encephalopathy (HE), SBP and variceal bleeding. ${ }^{99}$ These disturbances in gut microbiota lead to various bacterial complications in cirrhosis. Though antibiotics are the main therapeutic strategy, experimental studies are ongoing to investigate the use of pre-, pro-, symbiotic and fecal microbiota transplantation in patients with decompensated cirrhosis. ${ }^{99}$ Reshaping the microbiota in a beneficial manner may help to prevent complications of cirrhosis in the future.

\section{Bacterial infections in cirrhosis}

There have been drastic improvements in the management and prognosis of cirrhotic patients in the last few decades, but the rate of mortality due to infectious complications has not changed much. Bacterial infections are common in cirrhotics and are responsible for death in $30-50 \%$ of these patients. ${ }^{3}$ The most susceptible subset are those with alcoholic cirrhosis. ${ }^{82}$ Gram-negative enteric bacteria like E. coli, Klebsiella, Enterobacter species etc. are the most common causes and responsible for $75 \%$ of cases. Gram-positive bacteria like Staphyloccocus is responsible for around $20 \%$, and anaerobes for around 3\% of cases. ${ }^{100}$ Infection rates in hospitalized patients with cirrhosis are 4- to 5-fold higher than those among the general patient population. ${ }^{101}$ The most common infections that occur in these patients are represented by SBP (25-31\%). ${ }^{100}$ Other common infections are urinary tract infections (20-25\%), pneumonia (15-21\%), bacteremia $(12 \%)$ and soft tissue infections $(11 \%) .{ }^{100}$

For SBP, intravenous antibiotics for 5 days, intravenous albumin (to reduce the incidence of renal impairment) and long-term oral antibiotic prophylaxis (to prevent further episodes of SBP) is the standard of care. Multidrug-resistant organisms are also a concern now. In one of the large prospective trials, carried out by Fernandez et al., ${ }^{101}$ multidrugresistant bacteria $(18 \%)$ represented $4 \%, 14 \%$ and $35 \%$ of the community-acquired, healthcare-associated and nosocomial infections, respectively. Extended spectrum beta lactamase was the most common multidrug-resistant organism, followed by Pseudomonas aeruginosa, and methicillinresistant Staphylococcus aureus and Enterococcus faecium. Septic shock and mortality is high in multidrug-resistant infection patients, and it is currently recommended that empirical antibiotic prophylaxis is not effective for nosocomial infections.

\section{Tuberculosis}

The incidence of tuberculosis is increased in cirrhotic patients as compared to the general population, due to the immune dysfunction in the former. In a cohort study carried out in Denmark, the incidence rate of tuberculosis was 168.6 per 1 lakh population and was highest in men over 65 years of age. ${ }^{102}$ Another study carried out in western India showed the prevalence to be 15 times higher than in the general population; moreover, the authors showed extrapulmonary involvement (e.g. tubercular peritonitis) to be more frequent than in the general population. ${ }^{103}$

\section{Fungal infections}

Cirrhosis also increases the susceptibility to infection with the Cryptococcus neoformans fungus, which usually affects patients with acquired immune deficiency syndrome. ${ }^{104}$ It causes spontaneous peritonitis but with an elevation in lymphocyte count, and is associated with very high mortality due to late diagnosis. ${ }^{105}$ The probable pathogenetic mechanisms include percutaneous inoculation during paracentesis, gastrointestinal bleeding and BT. ${ }^{106}$

\section{Iron overload status and immunity}

End-stage cirrhosis can be associated with hepatic iron overload. Excess iron impairs the host immune system. It specifically impairs the cell-mediated immunity by impairing the Th1 response and also the functions of macrophages and neutrophils. ${ }^{107}$ Furthermore, it increases the $\mathrm{CD} 8^{+} \mathrm{T}$ cell count and reduces the $\mathrm{CD} 4^{+} \mathrm{T}$ cell count and response to common antigens. Ultimately, it increases susceptibility to organisms like E. coli, Vibrio and Listeria monocytogenes. ${ }^{107}$ Ashraflen et al. ${ }^{108}$ have shown that hepcidin is a link between liver disease and infections in hemochromatosis. Also, these patients are at increased risk of acquiring Vibrio vulnificus, with mortality of $50-60 \%$ being reported. ${ }^{109}$ Non-HFE iron overload has been shown to significantly associate with disease severity and reduced survival in patients with decompensated cirrhosis. ${ }^{110}$

\section{Systemic inflammatory response syndrome (SIRS),} sepsis and cirrhosis

Sepsis is defined as SIRS in the presence of a pathogenic infection or other injury (such as a crush injury) that can trigger the inflammatory immune response. Conventional SIRS criteria has a low sensitivity and specificity in cirrhotic patients, as it can be present in $10-30 \%$ without bacterial infections; moreover, these patients present low pulse rate and leucocyte count due to beta blocker therapy and hypersplenism, respectively, which can lead to underestimation of its prevalence. ${ }^{111}$ In SIRS, there is a cytokine storm with 
predominance of proinflammatory cytokines like TNF- $\alpha$, IL- 6 and IL-1, which leads to various changes in the coagulation cascade and circulatory system.

Cirrhotic patients are at increased risk for developing SIRS, as they have increased levels of endotoxins, TNF- $\alpha$, IL- 6 and nitric oxide and reduced levels of protein $C$ and coagulation factors. $^{8}$ SIRS is the cause of around $10 \%$ of hospital admissions among this patient population. In addition, SIRS occurs in patients with advanced cirrhosis and is correlated with death and portal hypertension-related complications such as $\mathrm{HE}$, variceal bleeding and renal failure. Bacterial-derived toxins (i.e. lipopolysaccharides from Gramnegative bacteria and peptidoglycans/lipopeptides from Gram-positive bacteria initiate a cascade of events that lead to a surge of proinflammatory cytokines which are not balanced by anti-inflammatory cytokines, leading to a state of excessive inflammation.

There is also increased production of superoxide from nitric oxide synthase during SIRS, leading to oxidative stress and increased vasodilatation. ${ }^{112}$ This leads to widespread inflammation and consequently to impaired oxygenation, cell necrosis, apoptosis and finally organ failure and death. It has been shown that cirrhotic patients develop a higher level of proinflammatory cytokines following a lipopolysaccharide challenge as compared to the healthy population. ${ }^{107,108}$ Prophylactic antibiotics in variceal bleeding, albumin in SBP and early diagnosis and treatment of bacterial infection are needed to improve outcome for sepsis and SIRS in cirrhosis.

The roles of biomarkers, CRP and procalcitonin have been studied in cirrhotic patients and found to be beneficial for detecting sepsis. Procalcitonin is an emerging biomarker of bacterial infection in these patients, and randomized controlled trials have found benefit in its use for detecting infection in these patients. ${ }^{113} \mathrm{Li}$ et al. ${ }^{114}$ studied the role of procalcitonin involving bacterial infection in cirrhotics and has found its sensitivity and specificity to be $81.5 \%$ and $87.3 \%$, respectively. Procalcitonin appears to be a better diagnostic marker than SIRS for detecting bacterial infection in the cirrhotic population. Elevated levels of procalcitonin and CRP have been shown to correlate with the outcome of sepsis in cirrhotics. ${ }^{111}$ CRP levels remain persistently elevated in the majority of patients, despite resolution of the bacterial infections. ${ }^{111}$ The role of newer markers of acute phase reactants, such as lipopolysaccharide-binding proteins, SCD14, midregion proadrenomedullin etc., still need to be studied in the cirrhotic population.

ACLF is a distinctive entity involving both acute and chronic insults to the liver and has a high short-term mortality. Host immune dysregulation is probably the leading factor in determining the severity of ACLF and its outcome. ${ }^{10}$ Host immune dysregulation is usually precipitated by bacterial infection, superimposed with other hepatotropic viruses, alcohol or drugs. In ACLF there is an imbalance between the exaggerated pro- and anti-inflammatory responses (i.e. between the systemic inflammatory response and the compensatory anti-inflammatory response). Prolonged immune paralysis predisposes an individual to sepsis, which increases the pro-inflammatory responses and results in a vicious cycle. ${ }^{115}$

To conclude, CAID is a complex phenomenon involving multiple mechanisms and leading to various complications. Gradually, researchers have been able to explore the underlying pathophysiology behind it by understanding the exact defect in each immune cell type and in systemic immunity.
Cirrhosis is an immunocompromised state accompanied by a higher predisposition to various infections, most common of which are the Gram-negative bacteria. Increased BT due to reduced intestinal motility and increased intestinal permeability is an important etiological factor for CAID.

Knowing the various defects in host immune system afflicted by CAID is of utmost importance for our attempts towards gaining a precise understanding and developing new diagnostic and therapeutic tools that will reduce the morbidity and mortality. There remain an unmet need for making a scoring system that includes the various clinical and biochemical markers and/or a specific biomarker which can identify that subset of cirrhotic patients which is most at risk of immune dysfunction and infection at an early stage. Despite there being an overall better understanding of various mechanisms of immune dysfunction in recent years, further research is needed to develop an effective preventive strategy to prevent its complications.

\section{Conflict of interest}

The authors have no conflict of interests related to this publication.

\section{Author contributions}

Design of the study and critical revision and final approval of the article (MTN), drafting of the article (PM).

\section{References}

[1] Christou L, Pappas G, Falagas ME. Bacterial infection-related morbidity and mortality in cirrhosis. Am J Gastroenterol 2007;102:1510-1517. doi: 10.1111/j.1572-0241.2007.01286.x.

[2] Albillos A, Lario M, Álvarez-Mon M. Cirrhosis-associated immune dysfunction: distinctive features and clinical relevance. J Hepatol 2014;61:13851396. doi: 10.1016/j.jhep.2014.08.010.

[3] Tandon P, Garcia-Tsao G. Bacterial infections, sepsis, and multiorgan failure in cirrhosis. Semin Liver Dis 2008;28:26-42. doi: $10.1055 / \mathrm{s}-2008-$ 1040319.

[4] Wiest R, Lawson M, Geuking M. Pathological bacterial translocation in liver cirrhosis. J Hepatol 2014;60:197-209. doi: 10.1016/j.jhep.2013.07.044.

[5] Runyon BA, Squier S, Borzio M. Translocation of gut bacteria in rats with cirrhosis to mesenteric lymph nodes partially explains the pathogenesis of spontaneous bacterial peritonitis. J Hepatol 1994;21:792-796. doi: doi. org/10.1016/S0168-8278(94)80241-6.

[6] Garcia-Tsao G, Wiest R. Gut microflora in the pathogenesis of the complications of cirrhosis. Best Pract Res Clin Gastroenterol 2004;18:353-372. doi: 10.1016/j.bpg.2003.10.005

[7] Thalheimer U, Triantos CK, Samonakis DN, Patch D, Burroughs AK. Infection, coagulation, and variceal bleeding in cirrhosis. Gut 2005;54:556-563. doi: $10.1136 /$ gut.2004.048181.

[8] Bonnel AR, Bunchorntavakul C, Reddy KR. Immune dysfunction and infections in patients with cirrhosis. Clin Gastroenterol Hepatol 2011;9:727-738. doi: $10.1016 / j . c g h .2011 .02 .031$.

[9] Duddempudi AT. Immunology in alcoholic liver disease. Clin Liver Dis 2012; 16:687-698. doi: 10.1016/j.cld.2012.08.003.

[10] Sipeki N, Antal-Szalmas P, Lakatos PL, Papp M. Immune dysfunction in cirrhosis. World J Gastroenterol 2014;20:2564-2577. doi: 10.3748/wjg. v20.i10.2564.

[11] Neish AS. Microbes in gastrointestinal health and disease. Gastroenterology 2009;136:65-80. doi: 10.1053/j.gastro.2008.10.080

[12] Newton K, Dixit VM. Signaling in innate immunity and inflammation. Cold Spring Harb Perspect Biol 2012;4. pii: a006049. doi: 10.1101/cshperspect. a006049.

[13] Kawai T, Akira S. Innate immune recognition of viral infection. Nat Immunol 2006;7:131-137. doi: 10.1038/ni1303.

[14] Wagner $\mathrm{H}$, Bauer S. All is not Toll: new pathways in DNA recognition. J Exp Med 2006;203:265-268. doi: 10.1084/jem.20052191.

[15] Beutler B. Innate immunity: an overview. Mol Immunol 2004;40: 845-859. 
[16] Antoniades CG, Wendon J, Vergani D. Paralysed monocytes in acute on chronic liver disease. J Hepatol 2005;42:163-165. doi: 10.1016/j.jhep. 2004.12.005.

[17] Gao B, Jeong WI, Tian Z. Liver: An organ with predominant innate immunity. Hepatology 2008;47:729-736. doi: 10.1002/hep.22034.

[18] Ramadori G, Christ B. Cytokines and the hepatic acute-phase response. Semin Liver Dis 1999;19:141-155. doi: 10.1055/s-2007-1007106.

[19] Liu C, Xu Z, Gupta D, Dziarski R. Peptidoglycan recognition proteins: a novel family of four human innate immunity pattern recognition molecules. J Biol Chem 2001;276:34686-34694. doi: 10.1074/jbc.M105566200.

[20] Bell JK, Mullen GE, Leifer CA, Mazzoni A, Davies DR, Segal DM. Leucine-rich repeats and pathogen recognition in Toll-like receptors. Trends Immunol 2003;24:528-533.

[21] Liu S, Gallo DJ, Green AM, Williams DL, Gong X, Shapiro RA, et al. Role of toll-like receptors in changes in gene expression and NF-kappa B activation in mouse hepatocytes stimulated with lipopolysaccharide. Infect Immun 2002; 70:3433-3442.

[22] Nishimura M, Naito S. Tissue-specific mRNA expression profiles of human toll-like receptors and related genes. Biol Pharm Bull 2005;28:886-892.

[23] Yang L, Seki E. Toll-like receptors in liver fibrosis: cellular crosstalk and mechanisms. Front Physiol 2012;3:138. doi: 10.3389/fphys.2012.00138.

[24] Seki E, Brenner DA. Toll-like receptors and adaptor molecules in liver disease: update. Hepatology 2008;48:322-335. doi: 10.1002/hep.22306.

[25] Roh YS, Seki E. Toll-like receptors in alcoholic liver disease, non-alcoholic steatohepatitis and carcinogenesis. J Gastroenterol Hepatol 2013;28 Suppl 1:38-42. doi: $10.1111 /$ jgh.12019.

[26] Hornung V, Rothenfusser S, Britsch S, Krug A, Jahrsdörfer B, Giese T, et al. Quantitative expression of toll-like receptor 1-10 mRNA in cellular subsets of human peripheral blood mononuclear cells and sensitivity to CpG oligodeoxynucleotides. J Immunol 2002;168:4531-4537.

[27] Paik YH, Schwabe RF, Bataller R, Russo MP, Jobin C, Brenner DA. Toll-like receptor 4 mediates inflammatory signaling by bacterial lipopolysaccharide in human hepatic stellate cells. Hepatology 2003;37:1043-1055. doi: 10. 1053/jhep.2003.50182

[28] Brun P, Castagliuolo I, Pinzani M, Palù G, Martines D. Exposure to bacterial cell wall products triggers an inflammatory phenotype in hepatic stellate cells. Am J Physiol Gastrointest Liver Physiol 2005;289:G571-G578. doi: 10.1152/ajpgi.00537.2004.

[29] Thirunavukkarasu C, Uemura T, Wang LF, Watkins SC, Gandhi CR. Normal rat hepatic stellate cells respond to endotoxin in LBP-independent manner to produce inhibitor(s) of DNA synthesis in hepatocytes. J Cell Physiol 2005; 204:654-665. doi: 10.1002/jcp. 20366.

[30] Zhang X, Yu WP, Gao L, Wei KB, Ju JL, Xu JZ. Effects of lipopolysaccharides stimulated Kupffer cells on activation of rat hepatic stellate cells. World J Gastroenterol 2004;10:610-613.

[31] Bilzer M, Roggel F, Gerbes AL. Role of Kupffer cells in host defense and liver disease. Liver Int 2006;26:1175-1186. doi: 10.1111/j.1478-3231.2006. 01342.x.

[32] Vodovotz Y, Liu S, McCloskey C, Shapiro R, Green A, Billiar TR. The hepatocyte as a microbial product-responsive cell. J Endotoxin Res 2001;7: 365-373.

[33] Broering R, Lu M, Schlaak JF. Role of Toll-like receptors in liver health and disease. Clin Sci (Lond) 2011:121:415-426. doi: 10.1042/CS20110065.

[34] Aoyama T, Paik YH, Seki E. Toll-like receptor signaling and liver fibrosis. Gastroenterol Res Pract 2010;2010. pii: 192543. doi: 10.1155/2010/ 192543.

[35] Szabo G, Dolganiuc A, Mandrekar P. Pattern recognition receptors: a contemporary view on liver diseases. Hepatology 2006;44:287-298. doi: 10. 1002/hep. 21308

[36] Li L, Chen L, Hu L, Liu Y, Sun HY, Tang J, et al. Nuclear factor high-mobility group box1 mediating the activation of Toll-like receptor 4 signaling in hepatocytes in the early stage of nonalcoholic fatty liver disease in mice. Hepatology 2011;54:1620-1630. doi: 10.1002/hep.24552.

[37] Llorente C, Schnabl B. The gut microbiota and liver disease. Cell Mol Gastroenterol Hepatol 2015;1:275-284. doi: 10.1016/j.jcmgh.2015.04.003.

[38] Thompson AJ, Locarnini SA, Lau GK, Naoumov NV, Desmond PV, MommejaMarin $\mathrm{H}$, et al. Quantitative HBeAg levels and patterns of TLR2 and TLR4 expression on CD14+ monocytes during potent antiviral therapy for chronic hepatitis B. J Gastroenterol Hepatol 2005;20:A83.

[39] Pimentel-Nunes $P$, Roncon-Albuquerque R Jr, Dinis-Ribeiro M, Leite-Moreira AF. Role of Toll-like receptor impairment in cirrhosis infection risk: are we making progress? Liver Int 2011;31:140-141. doi: 10.1111/j.1478-3231. 2010.02334.x.

[40] Matsumura T, Degawa T, Takii T, Hayashi H, Okamoto T, Inoue J, et al. TRAF6-NF-kappaB pathway is essential for interleukin-1-induced TLR2 expression and its functional response to TLR2 ligand in murine hepatocytes. Immunology 2003;109:127-136.

[41] Pimentel-Nunes P, Roncon-Albuquerque R Jr, Gonçalves N, FernandesCerqueira C, Cardoso H, Bastos RP, et al. Attenuation of toll-like receptor 2-mediated innate immune response in patients with alcoholic chronic liver disease. Liver Int 2010;30:1003-1011. doi: 10.1111/j.1478-3231.2010. 02251.x.

[42] Riordan SM, Skinner N, Nagree A, McCallum H, McIver C], Kurtovic J, et al. Peripheral blood mononuclear cell expression of toll-like receptors and relation to cytokine levels in cirrhosis. Hepatology 2003;37:1154-1164. doi: 10.1053/jhep.2003.50180.

[43] Testro AG, Gow PJ, Angus PW, Wongseelashote S, Skinner N, Markovska V, et al. Effects of antibiotics on expression and function of Toll-like receptors 2 and 4 on mononuclear cells in patients with advanced cirrhosis. J Hepatol 2010;52:199-205. doi: 10.1016/j.jhep.2009.11.006.

[44] Wasmuth HE, Kunz D, Yagmur E, Timmer-Stranghöner A, Vidacek D, Siewert $\mathrm{E}$, et al. Patients with acute on chronic liver failure display "sepsis-like" immune paralysis. J Hepatol 2005;42:195-201. doi: 10.1016/j.jhep.2004. 10.019.

[45] Lin CY, Tsai IF, Ho YP, Huang CT, Lin YC, Lin C], et al. Endotoxemia contributes to the immune paralysis in patients with cirrhosis. J Hepatol 2007;46: 816-826. doi: 10.1016/j.jhep.2006.12.018.

[46] Stadlbauer V, Mookerjee RP, Hodges S, Wright GA, Davies NA, Jalan R. Effect of probiotic treatment on deranged neutrophil function and cytokine responses in patients with compensated alcoholic cirrhosis. J Hepatol 2008;48:945-951. doi: 10.1016/j.jhep.2008.02.015.

[47] Nischalke HD, Berger C, Aldenhoff K, Thyssen L, Gentemann M, Grünhage F, et al. Toll-like receptor (TLR) 2 promoter and intron 2 polymorphisms are associated with increased risk for spontaneous bacterial peritonitis in liver cirrhosis. J Hepatol 2011;55:1010-1016. doi: 10.1016/j.jhep.2011.02. 022.

[48] Bruns T, Reuken PA, Fischer J, Berg T, Stallmach A. Further evidence for the relevance of TLR2 gene variants in spontaneous bacterial peritonitis. J Hepatol 2012;56:1207-1208; author reply 1208-1209. doi: 10.1016/j. jhep.2011.09.010.

[49] Guarner-Argente C, Sánchez E, Vidal S, Román E, Concepción M, Poca M, et al. Toll-like receptor 4 D299G polymorphism and the incidence of infections in cirrhotic patients. Aliment Pharmacol Ther 2010;31:1192-1199. doi: $10.1111 / j .1365-2036.2010 .04291 . x$.

[50] Nakagawara A, Inokuchi K, Ikeda K, Kumashiro R, Tamada R. Decreased superoxide (O2-)-generating activity of blood monocytes from patients with hepatic cirrhosis. Hepatogastroenterology 1984;31:201-203.

[51] Hassner A, Kletter $Y$, Jedvab M, Aronson M, Shibolet S. Impaired monocyte function in liver cirrhosis. Lancet 1979;1:329-330.

[52] Hassner A, Kletter $Y$, Shlag D, Yedvab M, Aronson M, Shibolet S. Impaired monocyte function in liver cirrhosis. Br Med J (Clin Res Ed) 1981;282: 1262-1263.

[53] Holdstock G, Leslie B, Hill S, Tanner A, Wright R. Monocyte function in cirrhosis. J Clin Pathol 1982;35:972-979.

[54] Xing T, Li L, Cao H, Huang J. Altered immune function of monocytes in different stages of patients with acute on chronic liver failure. Clin Exp Immunol 2007;147:184-188. doi: 10.1111/j.1365-2249.2006.03259.x.

[55] Zimmermann HW, Seidler S, Nattermann J, Gassler N, Hellerbrand C, Zernecke A, et al. Functional contribution of elevated circulating and hepatic non-classical CD14CD16 monocytes to inflammation and human liver fibrosis. PLoS One 2010;5:e11049. doi: 10.1371/journal.pone.0011049.

[56] Zhang J, Feng G, Zhao Y, Zhang J, Feng L, Yang J. Association between lymphocyte-to-monocyte ratio (LMR) and the mortality of HBV-related liver cirrhosis: a retrospective cohort study. BMJ Open 2015;5:e008033. doi: 10.1136/bmjopen-2015-008033.

[57] Møller HJ. Soluble CD163. Scand J Clin Lab Invest 2012;72:1-13. doi: 10. 3109/00365513.2011.626868.

[58] Grønbaek H, Sandahl TD, Mortensen C, Vilstrup H, Møller HJ, Møller S. Soluble CD163, a marker of Kupffer cell activation, is related to portal hypertension in patients with liver cirrhosis. Aliment Pharmacol Ther 2012;36:173-180. doi: 10.1111/j.1365-2036.2012.05134.x.

[59] Waidmann O, Brunner F, Herrmann E, Zeuzem S, Piiper A, Kronenberger B. Macrophage activation is a prognostic parameter for variceal bleeding and overall survival in patients with liver cirrhosis. J Hepatol 2013;58:956-961. doi: 10.1016/j.jhep.2013.01.005.

[60] Gäbele E, Mühlbauer M, Paulo H, Johann M, Meltzer C, Leidl F, et al. Analysis of monocyte chemotactic protein-1 gene polymorphism in patients with spontaneous bacterial peritonitis. World J Gastroenterol 2009;15:5558-5562.

[61] Mühlbauer M, Bosserhoff AK, Hartmann A, Thasler WE, Weiss TS, Herfarth $\mathrm{H}$, et al. A novel MCP-1 gene polymorphism is associated with hepatic MCP-1 expression and severity of HCV-related liver disease. Gastroenterology 2003;125:1085-1093.

[62] Tonan T, Fujimoto K, Qayyum A, Morita Y, Nakashima O, Ono N, et al. CD14 expression and Kupffer cell dysfunction in non-alcoholic steatohepatitis: superparamagnetic iron oxide-magnetic resonance image and pathologic correlation. J Gastroenterol Hepatol 2012;27:789-796. doi: 10.1111/j. 1440-1746.2011.07057.x

[63] Stadlbauer V, Mookerjee RP, Wright GA, Davies NA, Jürgens G, Hallström S, et al. Role of Toll-like receptors 2,4 , and 9 in mediating neutrophil 
dysfunction in alcoholic hepatitis. Am J Physiol Gastrointest Liver Physiol 2009;296:G15-G22. doi: 10.1152/ajpgi.90512.2008

[64] Fiuza C, Salcedo M, Clemente G, Tellado JM. In vivo neutrophil dysfunction in cirrhotic patients with advanced liver disease. J Infect Dis 2000;182: 526-533. doi: 10.1086/315742.

[65] Mookerjee RP, Stadlbauer V, Lidder S, Wright GA, Hodges SJ, Davies NA et al. Neutrophil dysfunction in alcoholic hepatitis superimposed on cirrhosis is reversible and predicts the outcome. Hepatology 2007;46:831-840. doi: 10.1002/hep. 21737.

[66] Fiuza C, Salcedo M, Clemente G, Tellado JM. Granulocyte colony-stimulating factor improves deficient in vitro neutrophil transendothelial migration in patients with advanced liver disease. Clin Diagn Lab Immunol 2002;9: 433-439.

[67] Garg V, Garg H, Khan A, Trehanpati N, Kumar A, Sharma BC, et al. Granulocyte colony-stimulating factor mobilizes CD34(+) cells and improves survival of patients with acute-on-chronic liver failure. Gastroenterology 2012:142:505-512.e1. doi: 10.1053/j.gastro.2011.11.027.

[68] Singh V, Sharma AK, Narasimhan RL, Bhalla A, Sharma N, Sharma R. Granulocyte colony-stimulating factor in severe alcoholic hepatitis: a randomized pilot study. Am J Gastroenterol 2014;109:1417-1423. doi: 10.1038/ajg.2014.154.

[69] Nouri-Aria KT, Alexander G], Portmann BC, Hegarty JE, Eddleston AL, Williams R. T and B cell function in alcoholic liver disease. J Hepatol 1986; 2:195-207.

[70] Doi H, Iyer TK, Carpenter E, Li H, Chang KM, Vonderheide RH, et al. Dysfunctional $\mathrm{B}$-cell activation in cirrhosis resulting from hepatitis $\mathrm{C}$ infection associated with disappearance of CD27-positive B-cell population. Hepatology 2012;55:709-719. doi: 10.1002/hep.24689.

[71] Márquez M, Fernández-Gutiérrez C, Montes-de-Oca M, Blanco MJ, Brun F, Rodríguez-Ramos $\mathrm{C}$, et al. Chronic antigenic stimuli as a possible explanation for the immunodepression caused by liver cirrhosis. Clin Exp Immunol 2009;158:219-229. doi: 10.1111/j.1365-2249.2009.04005.x.

[72] van de Wiel A, Schuurman HJ, Kater L. Alcoholic liver disease: an IgAassociated disorder. Scand J Gastroenterol 1987;22:1025-1030.

[73] Silvain C, Patry C, Launay P, Lehuen A, Monteiro RC. Altered expression of monocyte IgA Fc receptors is associated with defective endocytosis in patients with alcoholic cirrhosis. Potential role for IFN-gamma. J Immunol 1995; $155: 1606-1618$.

[74] Massonnet B, Delwail A, Ayrault JM, Chagneau-Derrode C, Lecron JC, Silvain C. Increased immunoglobulin $A$ in alcoholic liver cirrhosis: exploring the response of $B$ cells to Toll-like receptor 9 activation. Clin Exp Immunol 2009;158:115-124. doi: 10.1111/j.1365-2249.2009.04004.x.

[75] Homann C, Varming K, Høgåsen K, Mollnes TE, Graudal N, Thomsen AC et al. Acquired $\mathrm{C} 3$ deficiency in patients with alcoholic cirrhosis predisposes to infection and increased mortality. Gut 1997; 40:544-549.

[76] Akalin HE, Laleli Y, Telatar H. Serum bactericidal and opsonic activities in patients with non-alcoholic cirrhosis. Q J Med 1985;56:431-437.

[77] Hillebrandt S, Wasmuth HE, Weiskirchen R, Hellerbrand $C$, Keppeler $H_{\text {, }}$ Werth $A$, et al. Complement factor 5 is a quantitative trait gene that modifies liver fibrogenesis in mice and humans. Nat Genet 2005;37:835-843. doi: $10.1038 / \mathrm{ng} 1599$.

[78] Strey CW, Markiewski M, Mastellos D, Tudoran R, Spruce LA, Greenbaum $\mathrm{LE}$, et al. The proinflammatory mediators C3a and C5a are essential for liver regeneration. J Exp Med 2003;198:913-923. doi: 10.1084/jem. 20030374.

[79] Propst-Graham KL, Preheim LC, Vander Top EA, Snitily MU, Gentry-Nielsen MJ. Cirrhosis-induced defects in innate pulmonary defenses against Streptococcus pneumoniae. BMC Microbiol 2007;7:94. doi: 10.1186/1471-21807-94.

[80] Altorjay I, Vitalis Z, Tornai I, Palatka K, Kacska S, Farkas G, et al. Mannosebinding lectin deficiency confers risk for bacterial infections in a large Hungarian cohort of patients with liver cirrhosis. J Hepatol 2010;53:484-491. doi: $10.1016 /$ j.jhep.2010.03.028.

[81] Wiest R, Garcia-Tsao G. Bacterial translocation (BT) in cirrhosis. Hepatology 2005;41:422-433. doi: 10.1002/hep.20632.

[82] Wyke RJ. Problems of bacterial infection in patients with liver disease. Gut 1987;28:623-641

[83] Hoefs JC, Canawati HN, Sapico FL, Hopkins RR, Weiner J, Montgomerie JZ. Spontaneous bacterial peritonitis. Hepatology 1982;2:399-407.

[84] Aldersley MA, Howdle PD. Intestinal permeability and liver disease. Eur ] Gastroenterol Hepatol 1999;11:401-403.

[85] Martini GA, Phear EA, Ruebner B, Sherlock S. The bacterial content of the small intestine in normal and cirrhotic subjects: relation to methionine toxicity. Clin Sci 1957; 16:35-51.

[86] Teltschik Z, Wiest R, Beisner J, Nuding S, Hofmann C, Schoelmerich J, et al. Intestinal bacterial translocation in rats with cirrhosis is related to compromised Paneth cell antimicrobial host defense. Hepatology 2012; 55:1154-1163. doi: 10.1002/hep.24789.
[87] Llovet JM, Bartolí R, Planas R, Cabré E, Jimenez M, Urban A, et al. Bacterial translocation in cirrhotic rats. Its role in the development of spontaneous bacterial peritonitis. Gut 1994;35:1648-1652.

[88] Chesta J, Lillo R, Defilippi C, Jouanee E, Massone MA, Maulén M, et al. Patients with liver cirrhosis: mouth-cecum transit time and gastric emptying of solid foods. Rev Med Chil 1991;119:1248-1253.

[89] Chang CS, Chen GH, Lien HC, Yeh HZ. Small intestine dysmotility and bacterial overgrowth in cirrhotic patients with spontaneous bacterial peritonitis. Hepatology 1998;28:1187-1190. doi: 10.1002/hep.510280504.

[90] Chesta J, Defilippi C, Defilippi C. Abnormalities in proximal small bowel motility in patients with cirrhosis. Hepatology 1993;17:828-832.

[91] Appenrodt B, Grünhage F, Gentemann MG, Thyssen L, Sauerbruch T, Lammert F. Nucleotide-binding oligomerization domain containing 2 (NOD2) variants are genetic risk factors for death and spontaneous bacterial peritonitis in liver cirrhosis. Hepatology 2010;51:1327-1333. doi: $10.1002 /$ hep. 23440 .

[92] Crossley IR, Williams R. Spontaneous bacterial peritonitis. Gut 1985;26: 325-331.

[93] Keshavarzian A, Holmes EW, Patel M, Iber F, Fields JZ, Pethkar S. Leaky gut in alcoholic cirrhosis: a possible mechanism for alcohol-induced liver damage. Am J Gastroenterol 1999;94:200-207. doi: 10.1111/j.15720241.1999.00797.X.

[94] Toh Y, Korenaga D, Maekawa S, Matsumata T, Muto Y, Ikeda T, et al. Assessing the permeability of the gastrointestinal mucosa after oral administration of phenolsulfonphthalein. Hepatogastroenterology 1997;44:1147-1151.

[95] Campillo B, Pernet P, Bories PN, Richardet JP, Devanlay M, Aussel C. Intestinal permeability in liver cirrhosis: relationship with severe septic complications. Eur J Gastroenterol Hepatol 1999;11:755-759.

[96] Pérez-Paramo M, Muñoz J, Albillos A, Freile I, Portero F, Santos M, et al. Effect of propranolol on the factors promoting bacterial translocation in cirrhotic rats with ascites. Hepatology 2000;31:43-48. doi: 10.1002/hep. 510310109 .

[97] Senzolo M, Cholongitas E, Burra P, Leandro G, Thalheimer U, Patch D, et al. beta-Blockers protect against spontaneous bacterial peritonitis in cirrhotic patients: a meta-analysis. Liver Int 2009;29:1189-1193. doi: 10.1111/j. 1478-3231.2009.02038.x.

[98] Bajaj JS, Ridlon JM, Hylemon PB, Thacker LR, Heuman DM, Smith S, et al. Linkage of gut microbiome with cognition in hepatic encephalopathy. Am J Physiol Gastrointest Liver Physiol 2012;302:G168-G175. doi: 10.1152/ ajpgi.00190.2011.

[99] Gómez-Hurtado I, Such J, Sanz Y, Francés R. Gut microbiota-related complications in cirrhosis. World J Gastroenterol 2014;20:15624-15631. doi: 10.3748/wjg.v20.i42.15624.

[100] Bunchorntavakul C, Chavalitdhamrong D. Bacterial infections other than spontaneous bacterial peritonitis in cirrhosis. World J Hepatol 2012;4: 158-168. doi: 10.4254/wjh.v4.i5.158.

[101] Fernández J, Acevedo J, Castro M, Garcia O, de Lope CR, Roca D, et al. Prevalence and risk factors of infections by multiresistant bacteria in cirrhosis: a prospective study. Hepatology 2012;55:1551-1561. doi: 10.1002/ hep. 25532.

[102] Thulstrup AM, Mølle I, Svendsen N, Sørensen HT. Incidence and prognosis of tuberculosis in patients with cirrhosis of the liver. A Danish nationwide population based study. Epidemiol Infect 2000;124:221-225.

[103] Baijal R, Praveenkumar HR, Amarapurkar DN, Nagaraj K, Jain M. Prevalence of tuberculosis in patients with cirrhosis of liver in western India. Trop Doct 2010;40:163-164. doi: 10.1258/td.2010.090463.

[104] Mabee CL, Mabee SW, Kirkpatrick RB, Koletar SL. Cirrhosis: a risk factor for cryptococcal peritonitis. Am J Gastroenterol 1995;90:2042-2045.

[105] Park WB, Choe YJ, Lee KD, Lee CS, Kim HB, Kim NJ, et al. Spontaneous cryptococcal peritonitis in patients with liver cirrhosis. Am J Med 2006;119: 169-171. doi: 10.1016/j.amjmed.2005.06.070.

[106] Saif MW, Raj M. Cryptococcal peritonitis complicating hepatic failure: case report and review of the literature. J Appl Res 2006;6:43-50.

[107] Khan FA, Fisher MA, Khakoo RA. Association of hemochromatosis with infectious diseases: expanding spectrum. Int J Infect Dis 2007;11: 482-487. doi: 10.1016/j.ijid.2007.04.007.

[108] Ashrafian H. Hepcidin: the missing link between hemochromatosis and infections. Infect Immun 2003;71:6693-6700.

[109] Kizer KW. Vibrio vulnificus hazard in patients with liver disease. West J Med 1994; 161:64-65.

[110] Noor MT, Tiwari M, Kumar R. Non-HFE iron overload as a surrogate marker of disease severity in patients of liver cirrhosis. Indian J Gastroenterol 2016;35:33-39. doi: 10.1007/s12664-016-0623-6.

[111] Jalan R, Fernandez J, Wiest R, Schnabl B, Moreau R, Angeli P, et al. Bacterial infections in cirrhosis: a position statement based on the EASL Special Conference 2013. J Hepatol 2014;60:1310-1324. doi: 10.1016/j.jhep.2014. 01.024.

[112] Guarner C, Soriano G, Tomas A, Bulbena O, Novella MT, Balanzo J, et al. Increased serum nitrite and nitrate levels in patients with cirrhosis: relationship to endotoxemia. Hepatology 1993;18:1139-1143. 
Noor M.T. et al: Immune dysfunction in cirrhosis

[113] Schuetz $P$, Albrich $W$, Mueller B. Procalcitonin for diagnosis of infection and guide to antibiotic decisions: past, present and future. BMC Med 2011;9:107. doi: 10.1186/1741-7015-9-107.

[114] Li CH, Yang RB, Pang JH, Chang SS, Lin CC, Chen CH, et al. Procalcitonin as a biomarker for bacterial infections in patients with liver cirrhosis in the emergency department. Acad Emerg Med 2011;18:121-126. doi: 10. 1111/j.1553-2712.2010.00991.x.

[115] Sarin SK, Choudhury A. Acute-on-chronic liver failure: terminology, mechanisms and management. Nat Rev Gastroenterol Hepatol 2016;13: 131-149. doi: 10.1038/nrgastro.2015.219. 